\title{
Buckling Analysis of Smart Material Plates Using Higher Order Theory
}

\author{
P. Ravikanth Raju ${ }^{1}$, J. Suresh Kumar ${ }^{2}$ M. V. Lakshmi Prakash ${ }^{3}$ \\ ${ }^{1}$ Dept of Mechanical Engineering, Malla Reddy College of Engineering \& Technology, Secunderabad -500100, \\ , India \\ ${ }^{2}$ Dept of Mechanical Engineering, JNTU College of Engineering, Hyderabad-500085, India \\ ${ }^{3}$ Professor (Retd.), Dept of Mechanical Engineering, JNTU College of Engineering, Hyderabad-500085, India.
}

\begin{abstract}
Smart structures are the structure where in piezoelectric layers are attached to elastic layers in patches or in distributed form. Among many types of smart or adaptive materials, piezoelectric materials are primarily use because, theoretical analysis of this material has been so well developed. In this paper an analytical procedure is developed, to investigate the buckling characteristics of smart material plates subjected to electromechanical loading based on higher order shear deformation theory. The solutions are obtained using Navier's method for symmetric and anti-symmetric cross ply composite laminates attached with piezoelectric layer with all four edges all simply supported. The results obtained in this paper have been compared with other authors.
\end{abstract}

Keywords: buckling characteristics, higher order theory, navier's method, piezoelectric material, smart structures.

\section{Introduction}

Smart materials also called as a new class of structures has been produced by sensors and actuators to perform self-monitoring and self-controlling system. Sensing and actuating the structure could be applied in many engineering applications such as aircraft structures, large space structures, satellites, automotive industries, sports goods, medical devices etc. by incorporating smart structures with piezoelectric devices. Rajan L. Wankhade et al [1] has considered piezoelectric composite laminated plates subjected to both electromechanical loading for carrying out buckling analysis. They have considered higher order shear deformation theory for performing analysis based on finite element method. The results obtained by them are verified with numerical solution available in the literature. Hsuan-Teh Hu et al [2] has carried finite element buckling analysis under uniaxial compressive loads for composite laminate skew plates, by employing a nonlinear constitutive model, which includes a non linear in-plane shear formulation and Tsai-Wu failure criterion for fiber composite laminate materials. They have presented the influences of plate aspect ratio, plate skew angle and laminate layup on buckling resistance of composite laminated skew plates. S. K. Singh and A. Chakrabarti [3] developed an efficient $\mathrm{C}^{0} \mathrm{FE}$ model based on higher order zigzag theory for carrying out buckling analysis of composite laminated plates. They showed that the results obtained by them with the present model are efficient in predicting buckling analysis of composite laminated plates. M. Mohan Kumar et al [4] has carried buckling analysis both numerically and experimentally for predicting critical buckling load. For validity of the analysis methodology, they compared the test results with FEA predictions. The obtained results shows the effect of aspect ratio, effect of orientation of fiber, length to thickness ratio and cut-out shape on buckling analysis of composite laminated plates. Hessameddin Yaghoobi et al [5] has employed an analytical method on the basis of first order shear deformation theory for analyzing the buckling of piezoelectric coupled plates with various boundary conditions. They have validated the obtained results with those in the literature and presented the critical buckling load of piezoelectric plates for different plate aspect ratios, actuator voltage, thickness of piezoelectric and boundary conditions. I. K. Oh et al [6] has performed postbuckling and vibration analysis for partially eccentric and fully symmetric piezoelectric composite laminated plates. Non-linear finite element equations are formulated for piezoelectric composite laminated plates subjected to themo electric loads based on layerwise displacement theory. Results obtained by them have demonstrated a methodology the decrease of thermal postbuckled deflection. Hui-Shen Shen [7] presented post buckling analysis of simply supported composite laminated plate with piezoelectric actuators subjected to combined electric, mechanical and thermal loads. He has assumed that, the temperature field is distributed uniformly over the plate surface and along the plate thickness. Perturbation technique has been adopted for determination of buckling loads. He also studied the effects of temperature rise, applied voltage, fiber orientations, transverse shear deformation, plate aspect ratio, geometric imperfections and stacking sequences. D.R. J. Owen and Z. H. Li [8] presented refined transverse vibration and buckling analysis based on local model. The examples presented by them are compared with classical plate theory and analytical solutions. Mansour Mohieddin Ghomshei et al [9] developed a finite 
element formulation for analyzing thermal buckling of FGM annular plates of different thickness subjected to thermal loads. Initially pre-buckling plane elasticity problem has been developed and then solved using finite element method for determining the distribution of in-plane forces. They have validated the numerical results with available literature values and then carried out the studies on various parameters such as taper parameter, thickness-to-radius ratio and boundary conditions on buckling load factor of plates. K Chandrashekhara and $\mathrm{K}$ Bhatia [10] have developed a finite element model for active buckling control of composite laminated plates using piezoelectric materials. Investigation has been carried on dynamic buckling behavior of composite laminated plate subjected to linearly increasing compressive load. They have demonstrated the effectiveness of smart materials in enhancing buckling loads and presented finite element solutions for composite laminated plates with simply supported and clamped boundary conditions. S. A. M. Ghannadpour et al [11] analyzed the buckling analysis of rectangular functionally graded plates using finite strip method under thermal loadings. They obtained the solution by the principle of minimum potential energy and corresponding eigen value problem. Effects of material and geometric properties on FGP's buckling temperature difference are determined. Kant et al [12] presented theoretical model, which has incorporated laminate deformations that accounts for effects of transverse normal and shear stresses. They evaluated the model with first order and a few higher order theories which have developed by other investigators. Solving the boundary value problem using Navier's technique they obtained the solutions in closed form. Based on first order shear deformation theory Liew et al [13] has presented an efficient meshfree formulation for static analysis of composite laminated plates and beams with integrated piezoelectric layers. They have taken piezoelectric stiffness into account and derived the formulation from variational principle. They found from results, actuator patches bonded on high strain regions have significant role in controlling deflections of laminated composite plates. Investigation has been carried out on functionally graded material plates subjected to electromechanical loading for stability analysis by Priyanka Jadhav et al [14]. They derived the finite element model with von-Karman hypothesis using first order shear deformation theory. Using principle of minimum potential energy governing equilibrium equation is obtained and by solving eigen value problem, solution for critical buckling load is obtained. Fariborz Heidary et al [15] have outlined linear response of piezothermoelastic plate based on finite element methods and Hamilton's principle. They presented numerical results for composite plate attached with piezoelectric layers subjected to mechanical and thermal loadings. They have suppressed the vibrations by electric potential differences across piezoelectric layers attached to surfaces of composite plate. Kant et al [16] has presented an analytical solution for cross-ply composite laminates attached with piezoelectric fiber-reinforced composite actuators under bidirectional bending. For analyzing smart material plates subjected to electromechanical loading, a higher order shear and normal deformation theory has been used.

\section{Higher Order Shear Deformation Theory With Piezoelectric Effect}

In formulating the higher order shear deformation theory, a rectangular plate of $0 \leq \mathrm{x} \leq \mathrm{a} ; 0 \leq \mathrm{y} \leq \mathrm{b}$ bonded with piezoelectric layer is considered.

In order to approximate 3D-elasticity plate problem to a $2 \mathrm{D}$ one, the displacement components $\mathrm{u}(\mathrm{x}, \mathrm{y}$, $\mathrm{z}, \mathrm{t}), \mathrm{v}(\mathrm{x}, \mathrm{y}, \mathrm{z}, \mathrm{t})$ and $\mathrm{w}(\mathrm{x}, \mathrm{y}, \mathrm{z}, \mathrm{t})$ at any point in the plate are expanded in terms of the thickness coordinate. The displacement field which assumes $\mathrm{w}(\mathrm{x}, \mathrm{y}, \mathrm{z})$ constant through the plate thickness and thus setting $\varepsilon_{\mathrm{z}}=0$ is expressed as [12]:

$$
\left.\begin{array}{l}
u(x, y, z)=u_{o}(x, y)+z \theta_{x}(x, y)+z^{2} u_{o}^{*}(x, y)+z^{3} \theta_{x}^{*}(x, y) \\
v(x, y, z)=v_{o}(x, y)+z \theta_{y}(x, y)+z^{2} v_{o}^{*}(x, y)+z^{3} \theta_{y}^{*}(x, y) \\
w(x, y, z)=w_{o}(x, y)
\end{array}\right\}
$$

Where the parameters $\mathrm{u}_{0}, \mathrm{v}_{0}$ and $\mathrm{w}_{\mathrm{o}}$ denote the displacements of a point $(\mathrm{x}, \mathrm{y})$ on the midplane. The functions $\theta_{\mathrm{x}}$, $\theta_{\mathrm{y}}$ are rotations of the normal to the midplane about $\mathrm{y}$ and $\mathrm{x}$-axes, respectively.

Piezoelectric coupling involving mechanical and electrical excitation can be expressed in terms of stresses and strains as [13]:

$$
\left\{\begin{array}{l}
\sigma_{x} \\
\sigma_{y} \\
\tau_{x y} \\
\tau_{y z} \\
\tau_{x z}
\end{array}\right\}=\left[\begin{array}{ccccc}
Q_{11} & Q_{12} & Q_{13} & 0 & 0 \\
Q_{21} & Q_{22} & Q_{23} & 0 & 0 \\
Q_{31} & Q_{32} & Q_{33} & 0 & 0 \\
0 & 0 & 0 & Q_{44} & Q_{45} \\
0 & 0 & 0 & Q_{54} & Q_{55}
\end{array}\right]^{L}\left\{\begin{array}{l}
\varepsilon_{x} \\
\varepsilon_{y} \\
\gamma_{x y} \\
\gamma_{y z} \\
\gamma_{z x}
\end{array}\right\}^{L}-\left[\begin{array}{ccc}
0 & 0 & e_{31} \\
0 & 0 & e_{32} \\
0 & 0 & e_{33} \\
0 & e_{24} & 0 \\
e_{15} & 0 & 0
\end{array}\right]^{L}\left\{\begin{array}{l}
-\frac{\partial \xi(x, y, z)}{\partial x} \\
-\partial \xi(x, y, z) \\
\partial y \\
-\frac{\partial \xi(x, y, z)}{\partial z}
\end{array}\right\}^{L}
$$


Where $\sigma, \mathrm{Q}, \varepsilon$, e, and $\mathrm{E}$ are stress vector, elastic constant matrix, strain vector, piezoelectric constant matrix and electric field intensity vector respectively. When piezoelectric constant matrix [e] is unavailable it can be expressed in piezoelectric strain constant matrix [d] as [13]:

$$
[\mathrm{e}]=[\mathrm{Q}][\mathrm{d}]^{\mathrm{t}}
$$

Where

$$
[\mathrm{d}]^{\mathrm{t}}=\left[\begin{array}{ccc}
0 & 0 & d_{31} \\
0 & 0 & d_{32} \\
0 & 0 & d_{33} \\
0 & d_{24} & 0 \\
d_{15} & 0 & 0
\end{array}\right]
$$

The governing equations of displacement model will be derived using the principle of virtual work as [15]: $\int_{0}^{T}(\delta U+\delta V-\delta K) d t=0$

Where

$$
\begin{aligned}
& \delta U= \int_{A}\left\{\int_{-h / 2}^{h / 2}\left[\sigma_{x} \delta \in_{x}+\sigma_{y} \delta \in_{y}+\tau_{x y} \delta \gamma_{x y}+\tau_{x z} \delta \gamma_{x z}+\tau_{y z} \delta \gamma_{y z}\right] d z\right\} d x d y \\
& \delta \mathrm{V}=-\int\left(\mathrm{q}_{0}+\overline{\mathrm{w}}_{\mathrm{x}} \frac{\partial \mathrm{w}_{\mathrm{o}}}{\partial \mathrm{x}} \frac{\delta \partial \mathrm{w}_{\mathrm{o}}}{\partial \mathrm{x}}+\overline{\mathrm{N}}_{\mathrm{xy}} \frac{\partial \mathrm{w}_{\mathrm{o}}}{\partial \mathrm{y}} \frac{\delta \partial \mathrm{w}_{\mathrm{o}}}{\partial \mathrm{x}}+\overline{\mathrm{N}}_{\mathrm{yx}} \frac{\partial \mathrm{w}_{\mathrm{o}}}{\partial \mathrm{x}} \frac{\delta \partial \mathrm{w}_{\mathrm{o}}}{\partial \mathrm{y}}+\overline{\mathrm{N}}_{\mathrm{y}} \frac{\partial \mathrm{w}_{\mathrm{o}}}{\partial \mathrm{y}} \frac{\delta \partial \mathrm{w}_{\mathrm{o}}}{\partial \mathrm{y}}\right) \mathrm{dx} \mathrm{dy} \\
& \delta K= \int_{A}\left\{\int _ { - h / 2 } ^ { h / 2 } \rho _ { 0 } \left[\left(\dot{u}_{0}+Z \dot{\theta}_{x}+Z^{2} \dot{u}_{0}^{*}+Z^{3} \dot{\theta}_{x}^{*}\right)\left(\delta \dot{u}_{0}+Z \delta \dot{\theta}_{x}+Z^{2} \delta \dot{u}_{0}^{*}+Z^{3} \delta \dot{\theta}_{x}^{*}\right)+\right.\right. \\
&\left(\dot{v}_{0}+Z \dot{\theta}_{y}+Z^{2} \dot{v}_{0}^{*}+Z^{3} \dot{\theta}_{y}^{*}\right)\left(\delta \dot{v}_{0}+Z \delta \dot{\theta}_{y}+Z^{2} \delta \dot{v}_{0}^{*}+Z^{3} \delta \dot{\theta}_{y}^{*}\right)+ \\
&\left.\left.\dot{w}_{0} \delta \dot{w}_{0}\right] d z\right\} d x d y
\end{aligned}
$$

Integrating Eq. 4 through the thickness of the laminate, and rewriting in-plane force, moment resultants, transverse force resultants and inertias in matrix, it is obtained as:

$$
\left\{\begin{array}{l}
F_{i} \\
F_{i}^{*} \\
-- \\
M_{r} \\
M_{r}^{*} \\
-- \\
F_{t} \\
F_{t}^{*}
\end{array}\right\}=\left[\begin{array}{lllll}
\bar{A} & \bar{B} & \overline{D_{b}} & \overline{\mathrm{O}} \\
\overline{\mathrm{O}} & \overline{\mathrm{O}} & \overline{D_{s}}
\end{array}\right]\left\{\begin{array}{l}
\varepsilon_{o} \\
\varepsilon_{o}^{*} \\
-- \\
\boldsymbol{L} \\
L^{*} \\
-- \\
\phi \\
\phi^{*}
\end{array}\right\}
$$

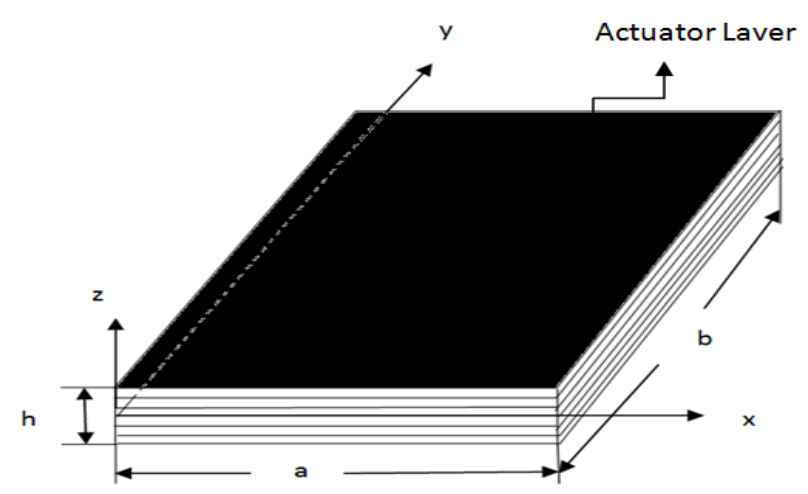

Fig. 1. Composite laminated plate attached with piezoelectric layer [16] 
The following are the mechanical and electrical in-plane boundary conditions for cross ply composite laminated plate attached with piezoelectric layer is:

At edges $\mathrm{x}=0$ and $\mathrm{x}=\mathrm{a}$

$\mathrm{v}_{0}=0, \mathrm{w}_{\mathrm{o}}=0, \theta_{\mathrm{y}}=0, \mathrm{M}_{\mathrm{x}}=0, \mathrm{v}_{0}{ }^{*}=0, \theta_{\mathrm{y}}^{*}=0, \mathrm{M}_{\mathrm{x}}{ }^{*}=0, \mathrm{~N}_{\mathrm{x}}=0, \mathrm{~N}_{\mathrm{x}}^{*}=0, \xi=0$

At edges $\mathrm{y}=0$ and $\mathrm{y}=\mathrm{b}$

$\mathrm{u}_{0}=0, \mathrm{w}_{\mathrm{o}}=0, \theta_{\mathrm{x}}=0, \mathrm{M}_{\mathrm{y}}=0, \mathrm{u}_{0}{ }^{*}=0, \theta_{\mathrm{x}}{ }^{*}=0, \mathrm{M}_{\mathrm{y}}{ }^{*}=0, \mathrm{~N}_{\mathrm{y}}=0, \mathrm{~N}_{\mathrm{y}}{ }^{*}=0, \xi=0$

Displacements at the mid plane are defined based on satisfaction of above boundary conditions and substituted in equations of equilibrium it is obtained as:

$$
\left[\begin{array}{ccccccccc}
K_{11} & K_{12} & K_{13} & K_{14} & K_{15} & K_{16} & K_{17} & K_{18} & K_{19} \\
K_{21} & K_{22} & K_{23} & K_{24} & K_{25} & K_{26} & K_{27} & K_{28} & K_{29} \\
K_{31} & K_{32} & K_{33}+N & K_{34} & K_{35} & K_{36} & K_{37} & K_{38} & K_{39} \\
K_{41} & K_{42} & K_{43} & K_{44} & K_{45} & K_{46} & K_{47} & K_{48} & K_{49} \\
K_{51} & K_{52} & K_{53} & K_{54} & K_{55} & K_{56} & K_{57} & K_{58} & K_{59} \\
K_{61} & K_{62} & K_{63} & K_{64} & K_{65} & K_{66} & K_{67} & K_{68} & K_{69} \\
K_{71} & K_{72} & K_{73} & K_{74} & K_{75} & K_{76} & K_{77} & K_{78} & K_{79} \\
K_{81} & K_{82} & K_{83} & K_{84} & K_{85} & K_{86} & K_{87} & K_{88} & K_{89} \\
K_{91} & K_{92} & K_{93} & K_{94} & K_{95} & K_{96} & K_{97} & K_{98} & K_{19}
\end{array}\right]\left\{\begin{array}{c}
U_{m n} \\
V_{m n} \\
W_{m n} \\
X_{m n} \\
Y_{m n} \\
U_{m n}^{*} \\
V_{m n}^{*} \\
X_{m n}^{*} \\
Y_{m n}^{*}
\end{array}\right\}=-V_{t}\left\{\begin{array}{c}
V_{1} \\
V_{2} \\
V_{3} \\
V_{4} \\
V_{5} \\
V_{6} \\
V_{7} \\
V_{8} \\
V_{9}
\end{array}\right\} \ldots \ldots(6)
$$

Where $N=N_{c r}\left(\lambda_{1} \alpha^{2}+\lambda_{2} \beta^{2}\right)$. For each value of $\mathrm{m}$ and $\mathrm{n}$, there is a value of $\mathrm{N}_{\mathrm{cr}}$. The critical buckling load is the smallest value of $\mathrm{N}_{\mathrm{cr}}(\mathrm{m}, \mathrm{n}) . \lambda_{1}$ and $\lambda_{2}$ are the constants depending on the type of compression. The composite laminated plate is bonded with piezoelectric layer and thickness of layer is small as compared to thickness of laminate.

With application of mechanical load the critical buckling load is expressed as [14]:

$$
\mathrm{P}_{\mathrm{cr}}=\mathrm{N}_{\mathrm{cr}} \mathrm{P}
$$

\section{Results And Discussions}

The material properties for composite laminate made of graphite/epoxy are [1]:

$$
\begin{aligned}
& E_{11}=181 G p a, E_{22}=10.3 G p a, E_{33}=10.3 G p a, G_{12}=7.17 G p a, \\
& G_{23}=2.87 G p a, G_{32}=7.17 G p a, v_{12}=0.35, v_{23}=v_{23}=0.38
\end{aligned}
$$

Material properties for piezoelectric layer made of PZT-5A are [1]:

$$
\begin{aligned}
& d_{31}=d_{32}\left(10^{-12} \mathrm{~m} / \mathrm{V}\right)=-171, d_{33}\left(10^{-12} \mathrm{~m} / \mathrm{V}\right)=374, d_{15}=d_{24}\left(10^{-12} \mathrm{~m} / \mathrm{V}\right)=-584 \\
& G_{12}=7.17 \mathrm{Gpa}, G_{23}=2.87 \mathrm{Gpa}, G_{32}=7.17 \mathrm{Gpa}
\end{aligned}
$$

Variation of nondimensionalized critical buckling load against different aspect ratio values for 3 layered composite laminated plates has been shown in Fig. 2. It is observed from figure that as the degree of orthotropic increases the variation of critical buckling load has been decreases. Fig 3 explains the variation of nondimensionalized critical buckling load against the different aspect ratios for a 5 layered composite laminated plate attached with piezoelectric layer at the top of surface. The maximum percentage variation of present approach with the available literature is $8.2 \%$ and $5.32 \%$ for $3 \& 5$ layered composite laminated plates respectively. Variation of side-to-thickness versus nondimensionalized critical buckling load for symmetric and anti-symmetric composite laminated plates attached with PZT-5A material has been demonstrated in Fig 4 \& 5 . With inclusion of piezoelectric effect, the minimum load at which the plate may go into instable condition has been increases. And also the critical buckling load increases with the increase of side-to-thickness ratio, this may be because of increase in stiffness. 


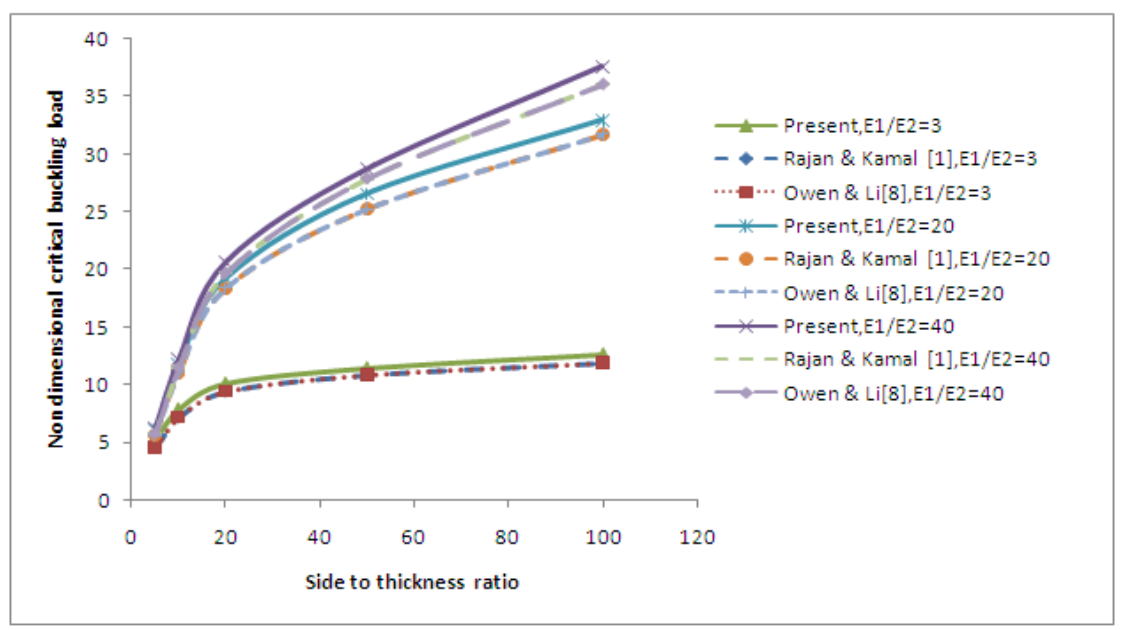

Fig. 2. Effect of side-to-thickness ratio (a/h) on nondimensionalized critical buckling load ( $\bar{N}$ ) under uniaxial compression for a simply supported composite laminated plate with piezoelectric effect for 3 layers

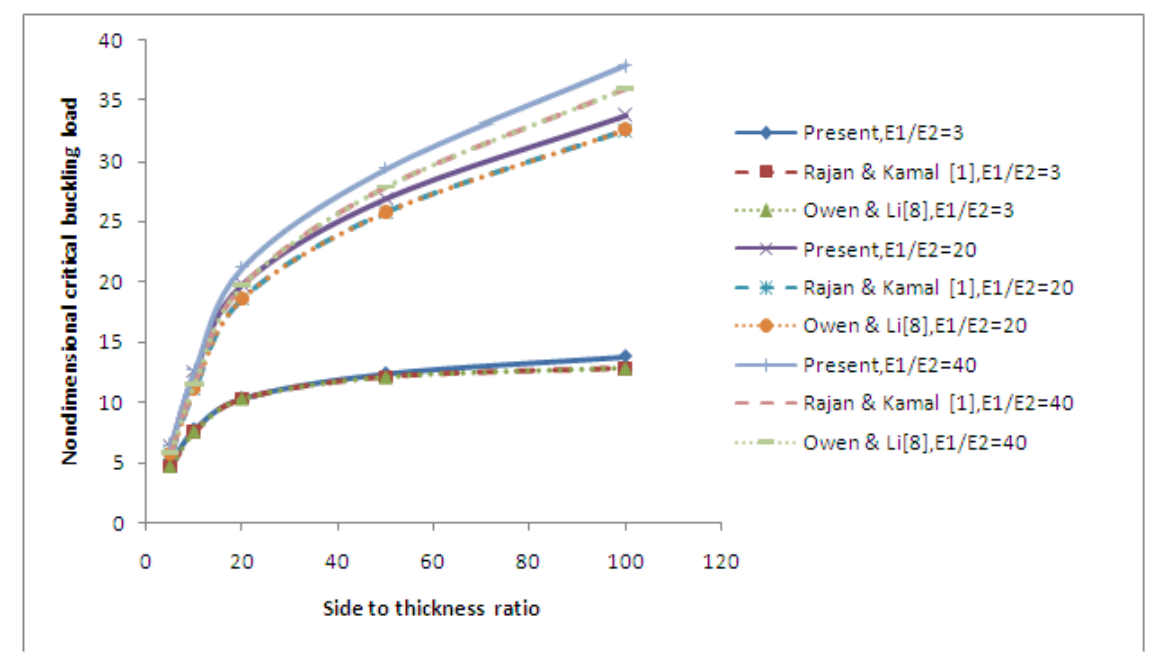

Fig. 3. Effect of side-to-thickness ratio (a/h) on nondimensionalized critical buckling load ( $\bar{N}$ ) under uniaxial compression for a simply supported composite laminated plate with piezoelectric effect for 5 layers

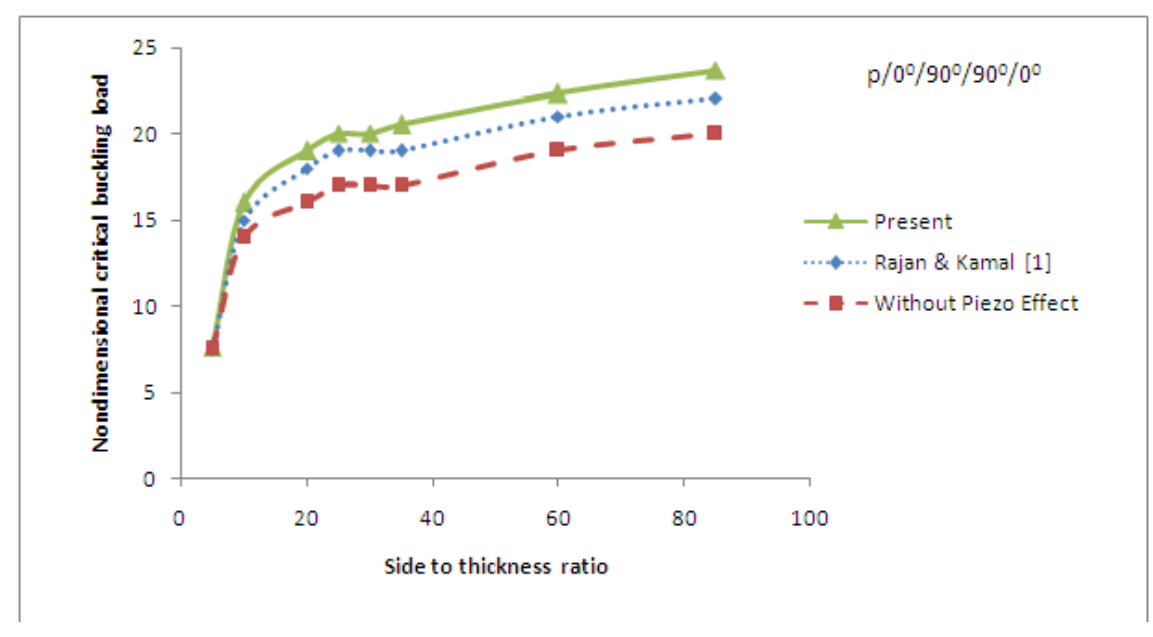

Fig. 4. Effect of side-to-thickness ratio (a/h) on nondimensionalized critical buckling load ( $\bar{N}$ ) under uniaxial compression for a simply supported symmetric cross ply piezolaminated composite plate 


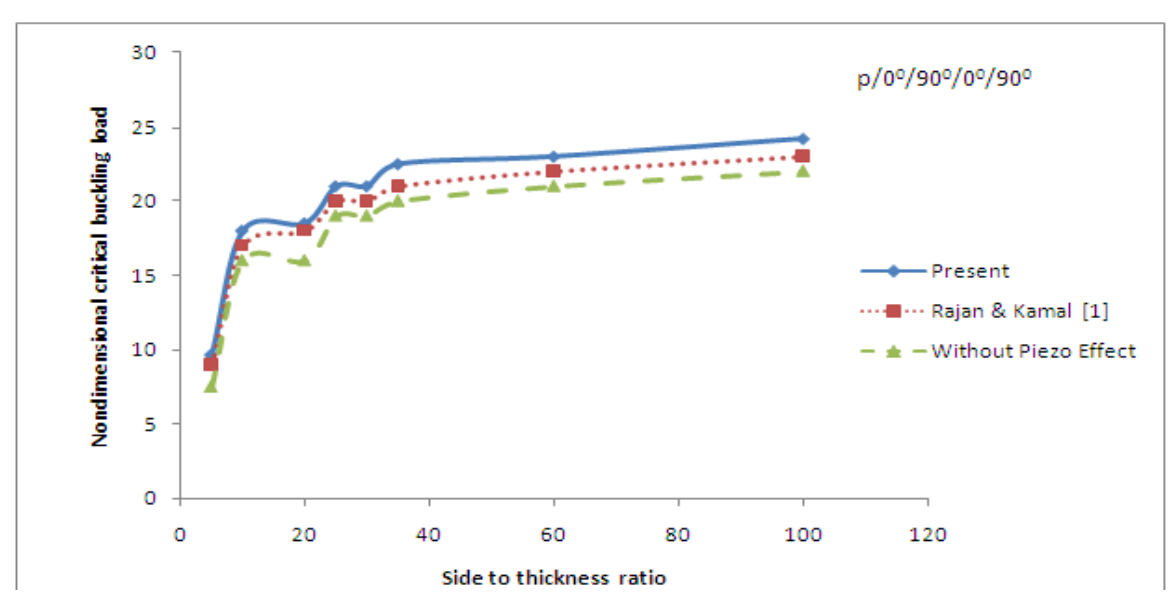

Fig. 5. Effect of side-to-thickness ratio (a/h) on non-dimensionalized critical buckling load $(\bar{N})$ under uniaxial compression for a simply supported anti-symmetric cross ply piezolaminated composite plate

\section{Conclusions}

In this paper a powerful analytical procedure has been developed for laminated composite plates attached with pieoelectric layer for finding the critical buckling load. Higher order shear deformation theory has been used for modeling laminated composite plate attached with piezoelecctric layer at top of the plate. Studies on influence of variation in ply orientation, degree of orthotropic and length-to-thickness ratio on nondimensionalized critical buckling load has been carried out. It may be observed from the results that, piezoelectric effect has a great influence on critical buckling load; it may be because of increase in stiffness. It is found from the results that the obtained values are in close agreement with available literature values.

\section{References}

[1] Rajan L. Wankhade, Kamal M. Bajoria, "Buckling Analysis of Piezolaminated Plates Using Higher Order Shear Deformation Theory", International Journal of Composite Materials, Vol. 3, 2013, PP 92-99.

[2] Hsuan-Teh Hu, Chia-Hao Yang and Fu-Ming Lin, "Buckling analyses of composite laminate skew plates with material nonlinearity" International Journal of Composites, No. 37, PP 26-36, 2006.

[3] S. K. Singh and A. Chakrabarti, "Buckling analysis of laminated composite plates using an efficient $\mathrm{C}^{\mathrm{O}} \mathrm{FE}$ model", International Journal of Solids and Structures, No. 9, PP 353-365, 2012.

[4] M. Mohan Kumar, Colins V Jacob, Lakshminarayana N, Puneeth BM and M. Nagabhushana, "Buckling Analysis of Woven Glass Epoxy Laminated Composite Plate", American Journal of Engineering Research, Vol. 2, Issue 7, PP 33-40, 2013.

[5] Hessameddin Yaghoobi and Iraj Rajabi, "Buckling Analysis of Three-Layered Rectangular Plate with Piezoelectric Layers", Journal of Theoretical and Applied Mechanics, Vol. 4, No. 51, PP 813-826, 2013.

[6] I. K. Oh, J. H. Han, I. Lee, "Postbuckling and Vibration Characteristics of Piezolaminated Composite Plate Subject To ThermoPiezoelectric Loads", Journal of Sound and Vibration, Vol. 233, No. 1, PP 19-40, 2000.

[7] Hui-Shen Shen, "Postbuckling of shear deformable laminated plates with piezoelectric actuators under complex loading conditions", International Journal of Solids and Structures, Vol. 38, PP 7703-7721, 2001.

[8] D. R. J. Owen and Z. H. Li, "A refined analysis of laminated plates by finite element displacement methods - II. Vibration and Stability", Journal of Computers and Structures, Vol. 26, No. 6, 1987, PP 915-923.

[9] Mansour Mohieddin Ghomshei and Vahid Abbasi, "Thermal buckling analysis of annular FGM plate having variable thickness under thermal load of arbitrary distribution by finite element method" Journal of Mechanical Science and Technology, Vol. 27, No. 4, 2013, PP 1031-1039.

[10] K Chandrashekhara and K Bhatia, "Active buckling control of smart composite plates-finite-element analysis", Journal of Smart Material Structures, Vol. 2, No. 31, 1993.

[11] S. A. M. Ghannadpour, H. R. Ovesy and M. Nassirnia, "Buckling analysis of functionally graded plates under thermal loadings using the finite strip method", Journal of Computers and Structures, Vol. 108-109, 2012, PP 93-99.

[12] T. Kant and K. Swaminathan, "Analytical solutions for the static analysis of laminated composite and sandwich plates based on a higher order refined theory", Journal of Composite Structures, Vol. 56, 2002, PP 329-344.

[13] K. M. Liew, H. K. Lim, M. J. Tan, and X. Q. He, "Analysis of laminated composite beams and plates with piezoelectric patches using the element-free Galerkin method", Journal of Computational Mechanics, Vol. 29, 2002, PP 486-497.

[14] Priyanka Jadhav, Kamal Bajoria, "Stability Analysis of Piezoelectric FGM Plate Subjected to Electro-mechanical Loading Using Finite Element Method", International Journal of Applied Science and Engineering, Vol. 11, No. 4, 2013, PP 375-391.

[15] Fariborz Heidary, M. Reza Eslami, "Piezo-control of forced vibrations of a thermoelastic composite plate", Journal of Composite Structures, Vol. 74, 2006, PP 99-105.

[16] S. M. Shiyekar, Tarun Kant, "Higher order shear deformation effects on analysis of laminates with piezoelectric fibre reinforced composite actuators", Journal of Composite Structures, Vol. 93, 2011, PP 3252-3261. 